\title{
Productive Trilingualism in Infancy: What Makes it Possible?
}

\author{
Simona Montanari ${ }^{1, *}$ \\ ${ }^{1}$ Department of Child and Family Studies, California State University, Los Angeles, USA \\ *Correspondence: Department of Child and Family Studies, California State University, Los Angeles, 5151 State \\ University Drive, Los Angeles, CA, 90032, USA \\ E-mail: smontan2@calstatela.edu
}

Received: February 16, 2013

Accepted: February 28, 2013

Online Published: March 13, 2013

doi:10.5430/wjel.v3n1p62

URL: http://dx.doi.org/10.5430/wjel.v3n1p62

\begin{abstract}
This article summarizes the results of a case study on the development of three languages in a child exposed to Tagalog, Spanish, and English from birth. The paper brings together findings from phonology, lexicon, word order, and language choice, providing a detailed picture of the emergence of the four components of three languages in infancy. The paper further explores the possible mechanisms upon which multiple language representations could be built, and then, it examines what characteristics of the environment and of the individual child might lead to the development and active use of three languages in infancy. The results suggest that the build-up of multiple language systems might follow naturally from trilingual exposure; yet, factors such as quantity and quality of language exposure, linguistic relatedness among languages, the child's personality, and the nature of the social context may dramatically influence trilingual competence in infancy and early childhood.
\end{abstract}

Keywords: trilingualism ; infancy; trilingual development; English; Tagalog; Spanish

\section{Introduction}

The past thirty years have witnessed a wealth of studies on Bilingual First Language Acquisition (BFLA). Scientific journals have devoted special issues to it; conferences, symposia, and colloquia specifically themed around BFLA have sprung throughout the world; textbooks on this particular topic have appeared in bookstores. BFLA researchers (see Genesee \& Nicoladis, 2009, for a review) have shown that bilingual children go through language development milestones at the same age as monolinguals; they acquire language-specific properties of the target languages early in development and similarly to monolingual peers; and they differentiate their languages from their earliest productions (Dual System hypothesis, as coined by Genesee, 1989). Evidence for language differentiation has been found in the area of phonology, lexicon, word order patterns, and language choice (see, again, Genesee \& Nicoladis, 2009). At the same time, evidence of cross-linguistic transfer of specific features from one language to the other has also been widely documented (see Yip \& Matthews, 2007, for a review) and it is now accepted that although BFL learners develop separate languages, the development of these languages is not autonomous but interdependent.

Unlike BFLA, the study of early trilingualism has not received much attention, at least until very recently, and research on the simultaneous development of three languages is literally in its infancy (Barnes, 2011; Chevalier, 2011; Kazzazi, 2011; Montanari, 2009a, 2009b, 2010, 2011a; Quay, 2001, 2008, 2011b). Most studies on trilingualism deal indeed with the acquisition of a third language later in childhood (such as through schooling), or with the role bilingualism plays when acquiring a third language (see Cenoz, 2003, Cenoz \& Hoffman, 2003, and Stavans \& Swisher, 2006, to name a few). Studies on Trilingual First Language Acquisition (TFLA), that is, on the development of three languages from birth, are either very little systematic in how they report input characteristics, data collection, analyses, etc. (see Quay, 2001, 2011a, and Hoffman, 2001, for a review); they often amount to a few case studies that explore specific themes such as cross-linguistic influence (Kazzazi, 2011), code-switching after age three (Edwards \& Dewaele, 2007; Hoffmann \& Stavans, 2007; Stavans \& Muchnik, 2008; Stavans \& Swisher, 2006), or the relationship between input and development in one language (Barnes, 2006; 2011); or they are anecdotal reports of individual cases of trilingual acquisition at times addressed to the general public (Maneva, 2004; Wang, 2008). In sum, systematic, longitudinal analyses of early trilingualism are scarce. 
One of the reasons for this dearth of studies on trilingual infants is perhaps the time-consuming nature of the methodology required for studying the development of three languages. At the same time, it has been argued that TFLA is an extension or a variant of BFLA and that results from trilingual studies should not revel anything "particularly new that we don't already know from BFLA studies" (comment from anonymous reviewer, 2009). Research in the past few years has shown that this is not the case. Quay (2011a), in an introduction to a special issue on early trilingualism, argues that TFLA is not the sum of three first languages, nor the addition of a third language to bilingualism. Rather, TFLA is a unique phenomenon with its own "traits," which should be studied in its own right, because it can help us understand not only how similar or different trilingualism is from monolingual and bilingual development, but also how language acquisition, in general, works. In this special issue, papers by Quay (2011b), Barnes (2011), Kazzazi (2011), and Montanari (2011a) clearly show that unlike bilinguals, trilingual children cannot be balanced or use their languages equally; rather, there is always a dominant language and weaker languages. The studies in this special issue also suggest that the quality of the input in each language as well as language-internal properties might tremendously affect the degree of proficiency in each language regardless of input amount or frequency. In sum, as Quay concludes (2011a), there is need to consider trilingual children "as speakers in their own right" (p. 6) and to contribute to this emerging field of inquiry that extends beyond BFLA.

This paper aims to contribute to this line of research and has two specific goals: first, it summarizes the results of a case study that systematically examined the emergence of three lexicons, separate phonological systems, different word orders, and distinct patterns of language choice in a child raised simultaneously with three languages - Tagalog, Spanish, and English (Montanari, 2009a, 2009b, 2010, 2011a). Although the results of individual analyses have been published elsewhere, this article aims to bring these findings together, providing a detailed picture of the emergence of the four components of three languages in one child. The second part of the article explores, first, the possible mechanisms upon which multiple language representations could be built, and then, it examines what characteristics of the environment and of the individual child might lead to the development and active use of three languages in infancy. Data from recent, preliminary analyses of TFLA in two sisters learning Italian, Spanish, and English in Los Angeles are also presented to complement the discussion.

The little existing research on TFLA reveals that not all children who experience trilingual exposure develop and become productive in three languages. Quay (2001, 2008), for example, who investigated two developing trilingual children's ability to modify their language use following the language preferences of the interlocutors - and hence speak three languages, found strikingly different results for the two children. In particular, in her first investigation (Quay, 2001), a developing Japanese-English-German trilingual boy growing up in Japan failed to show much use of the two minority languages while addressing his parents between $1 ; 1$ and 1;10, limiting himself to the use of Japanese. In a second study, however, Quay (2008) found that a two-year-old girl being raised in Chinese, Japanese, and English in Japan did use three languages with different language users, following her interlocutors' language preferences, their proficiency in each language, and their expectations as to appropriate language use. Similar findings appear in Chevalier (2011), who observed two developing trilingual children longitudinally from approximately two to three years of age. The children were growing up in Switzerland in mixed-language families where the language combinations were English, French, and Swiss German (the local language was French for one child and Swiss German for the other). Chevalier found that while one child was productive in all three languages from the start of the study, the second child understood the two minority languages but spoke predominantly the community language (Swiss German). Other case studies on specific aspects of early trilingual development also indicate either success (Barnes, 2006; Wang, 2008) or failure (Kazzazi, 2011; Stavans \& Swisher, 2006) in achieving productive trilingualism. In sum, currently, it is not clear what leads some children but not others to develop and become productive in different languages early on, especially when exposure to the three languages is available and somewhat balanced. What is clear, however, is that hearing, interacting in, and choosing from three different languages increase the complexity of early language development, providing the ideal ground to investigate what characteristics of the environment and of the individual child make the learning of three languages possible.

\section{A Case Study of Early Trilingual Development: Insights from Phonology, Lexicon, Word Order and Language Choice}

The goal of this section is to summarize the results of Montanari's (2009a), (2009b), (2010), and (2011a) studies. These studies document the emergence of three lexicons, separate phonological systems, different word orders, and distinct patterns of language choice in a developing trilingual girl (Kathryn). Kathryn was born and raised in Los Angeles, and, from birth, she was exposed to Tagalog through her mother and maternal grandparents, to Spanish 
through her father and paternal grandmother, and to English through her sister and, more indirectly, family conversations. Table 1 shows the child's exposure patterns during the study and her Mean Length of Utterance in words (MLUw) between 1;5.16 and 2;1.02.

Table 1: Kathryn's Language Exposure Patterns and MLUwords during the Study

\begin{tabular}{|c|c|c|c|}
\hline \multirow[t]{2}{*}{ Age } & \multicolumn{3}{|c|}{ LANGUAGE EXPOSURE } \\
\hline & $\%$ Tagalog & $\%$ Spanish & \% English \\
\hline \multirow[t]{3}{*}{ From birth to $2 ; 2$} & 48 & 29 & 23 \\
\hline & \multicolumn{3}{|c|}{ MEAN LENGTH OF UTTERANCE IN WORDS } \\
\hline & Tagalog MLUw & English MLUw & Spanish MLUw \\
\hline $1 ; 5.16$ & 1.00 & 1.00 & 1.00 \\
\hline $1 ; 9.29$ & 1.08 & 1.06 & 1.05 \\
\hline $2 ; 1.02$ & 1.20 & 1.17 & 1.17 \\
\hline
\end{tabular}

Kathryn's linguistic development from approximately 1;4 to 2;1 was followed through (a) weekly or bi-weekly diary records and (b) 16 ninety-minute audio recordings of her spontaneous speech while she was being addressed, in a natural and uncontrolled discourse context, in Tagalog by her mother, in Spanish by her father and/or grandmother, and in English by her sister and/or the author (see Montanari, 2009a, for more information on the child's language history, data collection and transcription). These data formed the basis on which the following research questions were answered:

1) Did the child build separate lexicons from the earliest months of language production?

2) Were her productions phonetically different, indicating that she was developing separate phonological systems?

3) Did word order vary from language to language, suggesting that separate ordering patterns were being acquired?

4) Did the child modify her patterns of language use following the language of her interlocutors?

Answers to these questions provide insights not only into whether the child was building separate language systems following trilingual exposure but also into the extent to which she was productive in three languages.

\subsection{The Emergence of Three Lexicons}

Montanari (2010) presents a chronological reconstruction of the child's trilingual lexicon between 1;4 and 2;0 and documents the appearance of translation equivalents (TEs) in Tagalog, English, and Spanish. The goal was to examine whether and how early Kathryn acquired such equivalents and therefore developed separate lexicons.

\subsubsection{Method}

The child's cumulative lexicon was reconstructed by taking the first occurrence of each lexical item from the diary notes and from the recording sessions' transcriptions and placing it, in its order of appearance, in a list. This list indicated, among other information, the word's pronunciation (in IPA), its language source, Kathryn's age when it first appeared, and the language context(s) in which it was produced, as defined by the language of the adult with whom Kathryn was interacting. TEs were identified operationally "on the basis of the child's interchangeable use of one word for another to refer to the same object, event or process" (as in Deuchar \& Quay, 2000, p. 53). The percentage of phonetically distinct equivalent terms was calculated over Kathryn's cumulative vocabulary at each month interval and the types of equivalents produced were examined (doublets and triplets) (see Montanari, 2010, for more information on methodology).

\subsubsection{Results}

Table 2 shows Kathryn's acquisition of words in different languages between 1;4 and 2;0 and the percentage of words with equivalents (TEs) over her cumulative vocabulary. As can be seen, the child's first words appeared around or slightly before the beginning of this study, and by age two, Kathryn had a total productive vocabulary of 297 unique words. Of this vocabulary, 22\% (68 words) were Tagalog lexical items, $28.3 \%$ ( 84 words) were English, 20.9\% (62 words) were Spanish, and $27.9 \%$ ( 83 words) were neutrals, i.e. items common to or ambiguous among languages, e.g. asul/azul, "blue," bye/bye, or okay/okay/okay (Tagalog words are in italics, English words are in bold italics, and Spanish items are in underlined italics). Neutrals were such a large part of the child's vocabulary because over $40 \%$ of Tagalog lexical items are loanwords from Spanish (30\%) and English (10\%) (Rau, 1992), and thus they can qualify as "words" in multiple languages. As a matter of fact, $60 \%$ of the 83 neutral words were words common to Tagalog and 
Spanish, 20.5\% were items common to Tagalog and English, and $18 \%$ of neutrals were words shared by all three languages (e.g. "okay").

Table 2: Kathryn's Number of Tagalog, Spanish, English, and Neutral Words between 1;4 and 2;0 and Percentage of Words with Translation Equivalents (TEs) over Cumulative Vocabulary

\begin{tabular}{llllllllll}
\hline Age & $1 ; 4$ & $1 ; 5$ & $1 ; 6$ & $1 ; 7$ & $1 ; 8$ & $1 ; 9$ & $1 ; 10$ & $1 ; 11$ & $2 ; 0$ \\
\hline Tagalog & 4 & 11 & 14 & 15 & 18 & 32 & 45 & 53 & 68 \\
Spanish & 3 & 5 & 6 & 13 & 18 & 31 & 41 & 54 & 62 \\
English & 1 & 8 & 8 & 12 & 14 & 33 & 51 & 69 & 84 \\
Neutral & 7 & 15 & 17 & 30 & 32 & 55 & 65 & 75 & 83 \\
TOTAL & 15 & 39 & 45 & 70 & 82 & 151 & 202 & 251 & 297 \\
\% of words with TE & 0 & 11.8 & 15.0 & 26.6 & 30.3 & 35.2 & 36.6 & 39.7 & 42.1 \\
\hline
\end{tabular}

Turning to the TE analysis, only a proportion of Kathryn's words had cross-language synonyms during her first two years of life. However, despite the large number of neutrals in Kathryn's vocabulary, phonetically distinct equivalents were identified from early on and their percentage increased with the gradual increase of new words. On average, $26.4 \%$ of Kathryn's words between 1;4 and 2;0 of age had phonetically distinct cross-language synonyms, and the percentage of doublets and triplets in her first 50 words was 28. These results parallel findings from bilingual studies (Deuchar \& Quay, 2000; Holowka, Brosseau-Lapré, \& Petitto, 2002; Lanvers, 1999; Pearson, Fernández, \& Oller, 1995), whose subjects also produced cross-language synonyms from their first words and had TEs for between one third and one fourth of their total vocabulary. If the $20-25 \%$ rate of TEs proposed by Genesee and Nicoladis (2009) is taken as evidence for lexical differentiation, these results indicate that, starting from between 1;6-1;7 of age, Kathryn was developing separate lexicons.

Table 3 shows the number and types of doublets and triplets produced by Kathryn between 1;4 and 2;0. As can be seen, phonetically distinct doublets abounded but non-neutral triplets were rare. As a matter of fact, the first such triplet did not appear until 1;7, and by age two Kathryn had only acquired ten phonetically distinct triplets.

Table 3: Number of Neutral and Phonetically Distinct Doublets and Triplets Produced by Kathryn between 1;4 and 2;0 (adapted from Montanari, 2010)

\begin{tabular}{llllllllll}
\hline Age & $1 ; 4$ & $1 ; 5$ & $1 ; 6$ & $1 ; 7$ & $1 ; 8$ & $1 ; 9$ & $1 ; 10$ & $1 ; 11$ & $2 ; 0$ \\
\hline DOUBLETS & & & & & & & & & \\
Phonetically Distinct & 0 & 2 & 3 & 7 & 10 & 19 & 23 & 34 & $44(39.3 \%)$ \\
Neutral & 3 & 9 & 11 & 23 & 25 & 45 & 53 & 63 & $68(60.7 \%)$ \\
TOTAL & 3 & 11 & 14 & 30 & 35 & 64 & 76 & 97 & $112(100 \%)$ \\
\hline TRIPLETS & & & & & & & & & \\
Phonetically Distinct & 0 & 0 & 0 & 1 & 1 & 4 & 8 & 9 & $10(25.0 \%)$ \\
Neutral - 2 words & 0 & 0 & 0 & 3 & 3 & 6 & 8 & 11 & $15(37.5 \%)$ \\
Neutral - 1 word & 4 & 6 & 6 & 7 & 7 & 10 & 12 & 12 & $15(37.5 \%)$ \\
TOTAL & 4 & 6 & 6 & 11 & 11 & 20 & 28 & 32 & $40(100 \%)$ \\
\hline
\end{tabular}

Note: Triplets are only counted as triplets and are not included in the doublet count.

Although triplets consisting of three different words were few, neutral triplets were not. As shown in the table, by the end of the study there were 15 triplets made up of a single word, and, most importantly, there were as many neutral triplets consisting of two different words (beybi/guagua/baby or lapis/lápiz/pen). Since Spanish and English loanwords make up over $40 \%$ of Tagalog lexical items (Rau, 1992), it is likely that the degree of cognation among Kathryn's languages contributed to the low percentage of phonetically distinct triplets. Also, Kathryn was consistently more exposed to Tagalog than Spanish and English, and Tagalog also appeared to be her dominant language. Thus it is natural that her equivalents often involved an item from her stronger language and an item from one of her weaker languages.

Despite restricted Spanish and English input, the number of triplets increased significantly between 1;8 and 1;9 and it continued to grow in the following months. This means that the large proportion of doublets did not prevent triplets from growing; rather, doublets paved the way for the child's acquisition of three equivalent terms. While the average time interval between the appearance of a word and its first equivalent during the entire period of study was indeed 66 days, it took only 30 days, on average, for the child to acquire a second equivalent, hence to form a triplet. This finding 
supports Lanvers' (1999) bilingual lexical bootstrapping hypothesis, i.e. the idea that equivalent learning is facilitated by the child's previous experience with a concept. In this case, the process of triplet formation was aided by the child's familiarity not only with a concept but also with the experience of learning equivalents. It is thus possible that in trilingual development the initial differentiation of the lexicon as evidenced by doublets facilitates the emergence of three lexical systems, similarly to the way bilinguals use their knowledge of two languages to learn a third language (Cenoz, 2003).

Take together, these findings provide robust evidence that despite the degree of cognation among her languages and reduced input in Spanish and English, Kathryn had sufficient lexical resources to interact and function appropriately in three languages. Besides the 40 concepts that she could express in all languages by age two, she had indeed labels for 112 additional concepts in at least two of her languages (44 phonetically distinct doublets and 68 Tagalog/Spanish or Tagalog/English neutrals), not to count all those words that she knew in only one language. Clearly, Kathryn was learning and using words in all three languages, demonstrating productive trilingualism from very early on, if not from the very first months of language production.

\subsection{The Development of Separate Phonological Systems}

The previous section has shown that Kathryn was building separate lexicons from a young age. However, separate lexicons do not necessarily imply the existence of differentiated phonological systems. In fact, a variety of studies have found that early lack of differentiation, delay, transfer, and un-uniform development are all possible paths in the course of bilingual phonological acquisition (Johnson \& Wilson, 2002; Kehoe, Lleó, \& Rakow, 2004; Keshavarz \& Ingram, 2002). Montanari (2011a) sets out to examine whether Kathryn's Tagalog, Spanish and English productions were differentiated on phonetic grounds as evidenced by varying accuracy levels in word-initial consonants and different phonetic inventories in each language.

The analyses are based on Articulatory Phonology (Browman \& Goldstein, 1992), an approach that treats phonology and phonetics as elements of a single system by positing that the units of control at the abstract level are the same as those at the physical level. The basic units of phonological contrast in this framework are gestures, that is, abstract characterizations of an articulator movement, or of a coordinated set of articulatory movements, that unfolds over time to form and release a certain degree of constriction at a specific location in the vocal tract. Constrictions can involve different organs or oral articulators (lips, tongue tip, tongue body and larynx); they can be formed at distinct locations (i.e. places of articulation); they can have different constriction degrees (i.e. manners of articulation); and they can be accompanied or not by glottal opening (for voiceless vs. voiced sounds). Contrasts involving different organs are predicted to emerge earlier than those involving different locations or degrees since between-organ contrasts are close to universal, while the emergence of within-organ contrasts require attunement to the language environment. Segments in this approach are defined as emergent phonological structures that consist of recurrent, spatio-temporally coordinated gestural routines.

\subsubsection{Method}

Four ninety-minute sessions, each separated by a one-week interval between Kathryn's age of 1;9.23 and 1;10.12, were used for the present analysis. All Tagalog-, Spanish-, and English-only words produced by the child during these sessions were transcribed narrowly in IPA and her accuracy levels in employing/reproducing the specific gestural properties of word-initial consonants (e.g. constricting organ, location, and degree) were compared across languages. The child's phonetic inventories in each language were also compared to each other to assess whether they displayed language-specific phonological structures (i.e. phones) and, therefore, differentiated phonological systems were being developed (see Montanari, 2011a, for more information on methodology).

\subsubsection{Results}

Figure 1 shows the percentage of organ, location, and degree matches above chance level in all three languages(Note $1)$. 


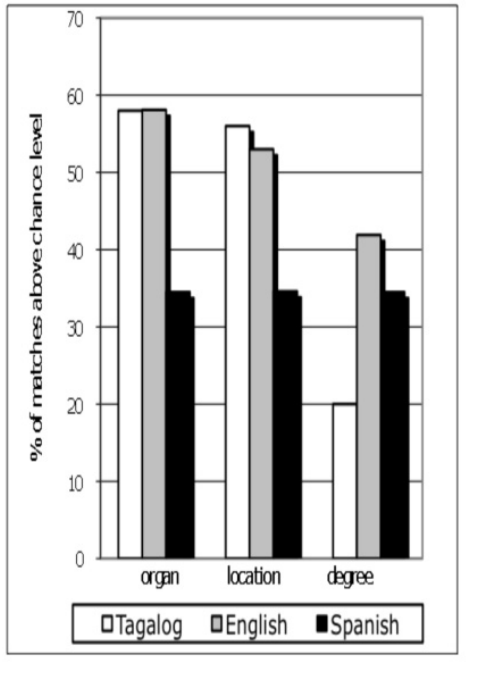

\begin{tabular}{ll}
\hline Performance * Language (Tagalog \& Spanish) \\
ORGAN & $\chi^{2}(1, N=72)=5.938, \mathrm{p}<.015$ \\
LOCATION & $\chi^{2}(1, N=65)=5.278, \mathrm{p}<.028$ \\
DEGREE & $\chi^{2}(1, N=66)=4.414, \mathrm{p}<.036$
\end{tabular}

\begin{tabular}{ll}
\hline Performance * Language (English \& Spanish) \\
ORGAN & $\chi^{2}(1, N=97)=4.830, p<.028$ \\
LOCATION & $\chi^{2}(1, N=79)=7.204, p<.007$
\end{tabular}

Performance * Language (Tagalog \& English)

DEGREE $\quad \chi^{2}(1, N=106)=13.544, p<.001$

Figure 1. Percentage of organ, location, and degree matches above chance level in Kathryn's Tagalog, English and Spanish word-initial consonants and results of chi-square tests between performance with different gestural properties and language (only significant associations are reported).

Figure 1: Percentage or organ, location, and degree matches above chance level in Kathryn's Tagalog, English and Spanish word-initial consonants and results of chi-square tests between performance with different gestural properties and language (only significant associations are reported)

The results of chi-square tests between performance and language reported in Figure 1 indicate that the child's productions significantly differed from language to language as to how well they reproduced some of the investigated gestural properties at the beginning of words. Tagalog and English words were different from Spanish ones in that they reproduced more faithfully the organ and location of adult word-initial segments; Spanish and English lexical items, on the other hand, were different from Tagalog ones because they replicated degree contrasts in word-initial position with more precision than Tagalog items. Therefore, in line with Articulatory Phonology predictions, between-organ contrasts had emerged in Tagalog, the language that Kathryn heard most at age 1;10, while they were still being developed in Spanish, the language in which she had the most limited number of language-specific word types (41 words at age 1;10, see Table 2 ). The majority of early organ and location errors in Spanish were indeed due to incorrect gestural phasing and to consonant harmony, developmental processes that have been reported in the literature as characteristic of the earliest stages of phonological development. These errors were rare in Tagalog and English suggesting that Kathryn was not, in these languages, at the same early stage of phonological development in which she was in Spanish. Spanish and English lexical items, however, displayed more precise degree contrasts in word-initial position than Tagalog items. Errors in Tagalog tended to affect the least frequent segments, that is, the only two fricatives that are found in native Tagalog words, $/ \mathrm{s} / \mathrm{and} / \mathrm{h} /$, which were often realized as the post-alveolar affricate and the glottal stop respectively. Errors of constriction degree were limited in those languages that displayed a larger variety of fricatives, i.e. English and Spanish.

Additional evidence that Kathryn's Tagalog, Spanish and English productions were differentiated on phonetic grounds comes from an analysis of the types of phonological structures (i.e. phones) she produced in each language 
(Table 4). A sound was considered part of Kathryn's inventory if it was executed with all the relevant gestures in at least $50 \%$ of the tokens for at least two different word types (similarly to Keshavarz \& Ingram, 2002).

Table 4: Phonological structures produced by Kathryn at age 1;10 (adapted from Montanari, 2011a)

$\begin{array}{ll}\text { TAGALOG } & \mathrm{p}, \mathrm{b}, \mathrm{t}, \mathrm{d}, \mathrm{g}, \underline{\mathrm{p}}, \mathrm{m}, \mathrm{n}, \underline{\mathrm{n}}, \mathrm{s}, \underline{\mathrm{h}}, \mathrm{t} \mathrm{f}, \mathrm{w}, \mathrm{j}, \mathrm{l} \\ \text { SPANISH } & \mathrm{p}, \mathrm{b}, \mathrm{t}, \mathrm{d}, \mathrm{k}, \mathrm{g}, \mathrm{m}, \mathrm{n}, \underline{\mathrm{n}}, \boldsymbol{\beta}, \mathrm{f}, \underline{\mathrm{s}}, \mathrm{t} f, \underline{\mathrm{w}}, \mathrm{j}, 1 \\ \text { ENGLISH } & \mathrm{p}, \mathrm{b}, \mathrm{t}, \mathrm{d}, \mathrm{k}, \mathrm{g}, \mathrm{m}, \mathrm{n}, \mathrm{f}, \underline{\mathrm{v}}, \boldsymbol{\theta}, \mathrm{d}, \mathrm{s}, \underline{\mathrm{z}}, \underline{\mathrm{h}}, \int, \mathrm{t} \int, \mathrm{w}, \mathrm{d}, \mathrm{j}, \mathrm{l}\end{array}$

Note: Underlined sounds were produced only in mid-word or final position.

As can be seen, Kathryn's Tagalog inventory displayed almost all Tagalog consonants; some sounds, including the Tagalog-specific glottal stop, although not found word-initially, were accurately executed in mid-word and in final position. The flap and the labiodental voiceless fricative ([f]) were not in the targets, so it could not be ascertained whether Kathryn could produce them or not. [k] was clearly the phone that was difficult for Kathryn, at least in Tagalog, since, the child never executed it in this language with all the relevant gestures. Kathryn's Spanish productions also displayed a quite advanced repertoire of Spanish consonants. Only the flap and the velar voiceless fricative $[\mathrm{x}]$ were in the targets but were never accurately reproduced, in line with the common finding that these sounds appear quite late even in monolinguals (Fabiano-Smith \& Goldstein, 2010a). The bilabial voiced fricative [ $\beta$ ], a sound unique to Spanish, appeared exclusively in Spanish but not in Tagalog and English productions. Finally, in English, Kathryn could master a variety of English structures including various language-specific phones $([\theta, \circlearrowright, \lambda])$.

Taken together, these findings suggest that Kathryn's emerging phonological systems were differentiated from the earliest stages of production. Her ability to match the various gestural properties of word-initial segments and the types of errors she produced varied across languages, indicating that she was at distinct stages of phonological development in each language. The complexity of her phonetic inventories also suggests that the child was developing phonological systems that were not only differentiated but also fairly advanced for her age.

\subsection{The Emergence of Differentiated Ordering Patterns}

The previous sections have shown that Kathryn was learning and producing words in Tagalog, Spanish, and English and that these words were phonetically differentiated according to their language. This section focuses on whether Kathryn could differentiate her productions at the multi-word level. Research with bilinguals has shown that the word orders produced by bilingual children with an MLU of 1.75 and above consistently reflect the different ordering patterns and properties specific to each input language (see Meisel, 2001, for a review). Yet, it is being debated whether early combinations, at a period when syntactic marking has yet to appear, reflect the patterns found in the input languages or rather some universal semantic, pragmatic, or syntactic principles. Montanari (2009b) examines word order in Kathryn's earliest multi-word combinations (when her MLUw was less than 1.5) to assess whether ordering patterns significantly varied from language to language, demonstrating that the child was in the process of developing separate syntactic systems.

\subsubsection{Method}

The data for the analyses come from the multi-word combinations produced by Kathryn between 1;7 and 2;1. Only those utterances that were productive (i.e. the words of which also appeared independently) and that were accompanied by explicit information as to their meaning were included. The types of combinations produced by the child (declaratives, imperatives, wh-questions, greetings, and modified noun phrases) were examined and their percentages in each language were calculated. Since Tagalog differs considerably from English and Spanish in its basic word order (Tagalog is predicate-initial; English and Spanish tend to be predicate-final), and since Spanish and English vary as to the extent to which they adhere to the predicate-final or SVO order (English is strictly SVO; Spanish has both orders depending on the information load that constituents carry in the discourse), the order of arguments with respect to predicates within declarative sentences was also examined and compared across languages. The frequencies of argument + predicate and of predicate + argument structures in the declarative utterances produced by the adults interacting with the child were also calculated and compared to the frequencies found in the child data (see Montanari, 2009b, for more information on methodology).

\subsubsection{Results}

The types of constructions produced by Kathryn in Tagalog, Spanish and English and their percentages are shown in Table 5. 
Table 5: Percentage of Combination Types (declaratives, modified NPs, greetings, imperatives and wh-questions) Produced by Kathryn in Tagalog, Spanish and English between 1;7 and 2;1 (number of tokens in parentheses)

\begin{tabular}{lccc}
\hline Age & Tagalog & Spanish & English \\
\hline \% Declaratives & $46.5(40)$ & $62.8(81)$ & $38.6(73)$ \\
\% Modified NP & $27.9(24)$ & $27.1(35)$ & $5.8(11)$ \\
\% Greetings & $10.5(9)$ & $3.1(4)$ & $8.5(16)$ \\
\% Imperatives & $9.3(8)$ & $3.9(5)$ & $4.8(9)$ \\
\% Wh-Questions & $5.8(5)$ & $3.1(4)$ & $42.3(80)$ \\
TOTAL & $100.0(86)$ & $100.0(129)$ & $100.0(189)$ \\
\hline
\end{tabular}

$\chi^{2}(8, N=404)=110.941, \mathrm{p}<.001$

The results of a chi-square test between combination types and language indicate significant cross-language differences $\left(\chi^{2}[8, N=404]=110.941, \mathrm{p}<.001\right)$ : wh-questions were almost absent from Tagalog and Spanish utterances whereas they were frequent in English. On the other hand, modified noun phrases abounded in Tagalog and Spanish but they were less common in English. Declaratives formed over $60 \%$ of the combinations produced in Spanish while being considerably less frequent in Tagalog and even more so in English. These findings seem to provide evidence that the child was learning different constructions at different times in her three languages. Structures that were or were being acquired in one language were not mastered in or were minimally transferred to other languages, suggesting that the development of different sentence types proceeds "along separate, non-intersecting lines for each language" (De Houwer, 1990, p. 338).

When the distribution of argument + predicate or predicate + argument sequences in each language were calculated, interesting target-dependent preferences were also found. Figure 2 reports the order of predicates with respect to arguments in both Kathryn's and the adults' declaratives.

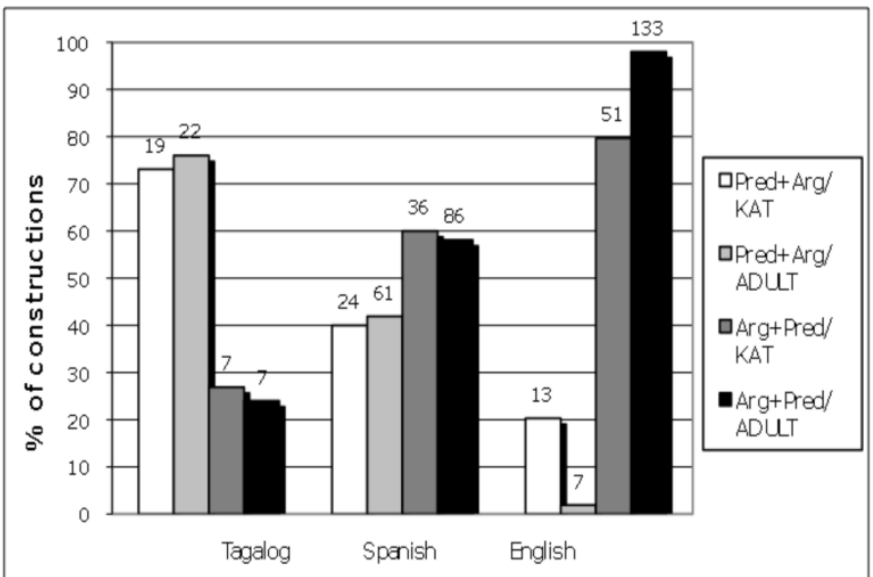

Figure 2. Argument + Predicate and Predicate + Argument constructions produced by Kathryn and the adult interlocutors in Tagalog, Spanish and English (adapted from Montanari, 2009b).

Figure 2: Argument + Predicate and Predicate + Argument constructions produced by Kathryn and the adult interlocutors in Tagalog, Spanish and English (adapted from Montanari, 2009b)

Although the numbers are small, the results show an overall preference for predicate + argument structures in Tagalog for both the child and her mother but they indicate the opposite trend for English combinations. On the other hand, there is more variation in Spanish multiword utterances which alternate between argument + predicate sequences and predicate + argument constructions in both Kathryn and the adults' speech. These results mirror the surface structures of basic sentences in Kathryn's input languages; thus, despite some instances of variation, the child appeared quite good at reproducing the basic word orders of each of her languages. A chi-square test applied to the argument + predicate and predicate + argument sequences produced by the child in each language indicates that there was a significant association between word order and language $\left(\chi^{2}[2, N=150]=22.306, \mathrm{p}<.001\right)$. These results confirm that Kathryn was displaying different ordering patterns depending on the language in which she was interacting and following input-dependent preferences. 
In sum, the analysis reported in this section indicates that Kathryn could learn and use separate ordering patterns not only before the appearance of clear morphological/syntactic markings but also in the context of three languages. Although it is unknown whether the child had developed some sort of language-specific combinatorial knowledge or rather she was just imitating the ordering patterns heard in adult speech, different word orders are testimony that the child was gradually building different syntactic systems and using three differentiated languages.

\subsection{Language Choice with Different Language Users}

After examining Kathryn's ability to differentiate her languages on the lexical, phonological, and syntactic level (linguistic competence), this section now turns to the child's communicative competence. Reporting the main findings of Montanari (2009a), this section focuses on Kathryn's ability to modify her patterns of language use following the language of her interlocutors. Recall that this was the topic of Quay's (2001; 2008) and Chevalier's (2011) studies, which revealed that trilingual-to-be children differ in the extent to which they can make active use of the minority languages when interacting with speakers of those languages. This section specifically examines Kathryn's patterns of language choice with Tagalog, Spanish, and English speakers at age 1;10 to assess: (1) whether evidence for pragmatic differentiation could be found even before age two and within a mixed language context, where the child was being simultaneously confronted by distinct language users; (2) whether lack of proficiency was responsible for her choice of one language over another; (3) whether the child's language choice was affected by the interlocutors' language preferences and their responses to language mixing.

\subsubsection{Method}

Four ninety-minute sessions, each separated by a one-week interval between Kathryn's age of 1;9.23 and 1;10.12, were used for the present analysis. In these sessions, the child was simultaneously interacting, in a natural and uncontrolled discourse context, with her Tagalog-speaking mother, her Spanish-speaking father and grandmother, and the English-speaking author. In order to examine whether the child showed sensitivity to the interlocutor's language, the frequencies of Tagalog, English, Spanish and mixed utterances produced by the child in each language context were calculated. Then, the child's instances of language mixing, which mainly consisted of one-word utterances in a language other than the addressee's, were analyzed in terms of her reconstructed trilingual lexicon to assess whether lexical gaps were responsible for the choice of one language over another. The final step was to assess whether there was a relationship between the child's language choice and the interlocutors' patterns of language use. For this part of the study, the distribution of the language(s) that the adult interlocutors used when addressing the child was calculated. The adults' communicative strategies, that is their responses to Kathryn's language mixing, were further examined qualitatively in terms of Lanza's (1997) parental discourse strategies towards child language mixing to see whether the interlocutors tended to negotiate a monolingual, a bilingual, or a trilingual context.

\subsubsection{Results}

Table 6 shows Kathryn's patterns of language choice in different language contexts. As can be seen, the child clearly differentiated her languages pragmatically: she used more Tagalog with her Tagalog-speaking mother, she increased her use of English with the English-speaking interlocutor, and resorted to more Spanish in the Spanish context. The results of a chi-square test applied to the Tagalog, English, Spanish, and mixed utterances addressed by the child to each interlocutor further indicate that the association between the child's patterns of language choice and the language of the interlocutors was significant $\left(\chi^{2}[6, N=217]=68.005, \mathrm{p}<.001\right)$. At the same, despite modifying her patterns of language use to match the language of her addressees, the child was still far from adult-like discourse separation. For instance, only $36.4 \%$ of her utterances were in Spanish in the Spanish context, and approximately 40 and 30\% of utterances in the English and Tagalog context respectively were in languages other than the interlocutor's. 
Table 6: Kathryn's Percentage of Tagalog, Spanish, English, and Mixed Utterances Addressed to Her Tagalog-speaking Mother, Her Spanish-speaking Father and Grandmother, and the English-speaking Author at Age $1 ; 10$ (number of tokens in parentheses)

\begin{tabular}{lccc}
\hline & $\begin{array}{c}\text { To Tagalog-speaking } \\
\text { mother }\end{array}$ & $\begin{array}{c}\text { To Spanish-speaking } \\
\text { father and grandmother }\end{array}$ & $\begin{array}{c}\text { To English- speaking } \\
\text { author }\end{array}$ \\
\hline \%Tagalog & $72.8(59)$ & $22.7(15)$ & $30.0(21)$ \\
\%Spanish & $14.8(12)$ & $36.4(24)$ & $8.6(6)$ \\
\%English & $9.9(8)$ & $39.4(26)$ & $60.0(42)$ \\
\%Mixed & $2.5(2)$ & $1.5(1)$ & $1.4(1)$ \\
TOTAL & $100.0(81)$ & $100.0(66)$ & $100.0(70)$ \\
\hline
\end{tabular}

$\chi^{2}(6, N=217)=68.005, \mathrm{p}<.001$

Table 7 shows the percentage of code-mixed words (tokens) with and without translation equivalents (TE) produced by Kathryn in the Tagalog, Spanish, and English context. As can be seen, over $80 \%$ of code-mixed tokens in the Tagalog and in the English context lacked a TE, indicating that mixes were due to vocabulary gaps. In the Spanish context, however, only $60 \%$ of code-mixed items did not have a Spanish TE, suggesting that there were variables other than proficiency affecting the amount and direction of language mixing.

Table 7: Percentage of Code-mixed Tokens with and without Translation Equivalents Produced by Kathryn in the Tagalog, Spanish and English Context at Age 1;10 (tokens in parentheses)

\begin{tabular}{lccc}
\hline & $\begin{array}{c}\text { To Tagalog-speaking } \\
\text { mother }\end{array}$ & $\begin{array}{c}\text { To Spanish-speaking } \\
\text { father and grandmother }\end{array}$ & $\begin{array}{c}\text { To English-speaking } \\
\text { author }\end{array}$ \\
\hline$\%$ words without TE & $81.8(18)$ & $59.6(25)$ & $82.4(23)$ \\
$\%$ words with TE & $18.2(4)$ & $40.4(17)$ & $18.1(5)$ \\
TOTAL & $100.0(22)$ & $100.0(42)$ & $100.0(28)$ \\
\hline
\end{tabular}

A detailed analysis of the interactions between the child and the adults indicates that their reactions to language mixing and the child's awareness of their multilingualism affected Kathryn's patterns of language choice. While the English-speaking author and the Tagalog-speaking mother had indeed a tendency to provide negative sanctioning to the child's mixing, that is, correct her as to the appropriate language choice, the Spanish-speaking interlocutors repeatedly showed comprehension and appreciation of her English utterances, involuntarily suggesting to her that her mixes were not only being understood but they were appropriate. In this way, despite not mixing languages, Kathryn's father and grandmother involuntarily socialized the child into mixing languages, especially those languages that they themselves spoke and understood. In addition, unlike the Tagalog and English-speaking adults, Kathryn's father and grandmother - the only speakers she could hear Spanish from - switched to English not only to address other family members, including their own spouses, but also to interact with each other, providing a crucial message as to appropriate language use in the Spanish context.

In conclusion, the results of this study indicate that Kathryn used different languages with distinct language users from very early on in development. However, switches to inappropriate languages were common due to vocabulary gaps, the interlocutors' acceptance of mixing, and the possibilities determined by the existence of multiple lexical resources and multiple language users.

\section{What Makes Productive Trilingualism in Infancy Possible?}

\subsection{Building Multiple Language Representations in Infant Trilingualism}

The previous section has provided an in-depth analysis of the emergence of the four components of three languages in infant trilingualism. This analysis has revealed that the development and active use of three languages in infancy is possible. Evidence from Kathryn's lexical, phonological, syntactic, and pragmatic development has revealed indeed that, from the first months of language production, the child was in the process of building multiple lexicons, separate phonological systems, different word ordering patterns, and distinct sets of pragmatic rules for the use of each of her three languages.

Current hypotheses are especially promising as far as revealing the possible mechanisms upon which the capacities for initial language discrimination and eventual trilingual development could be built. Research on infant speech 
perception has shown indeed that infants come to the world well equipped with the perceptual and memory capacities that are necessary for multilingual acquisition - the ability to capture differences as well as distributional regularities present in the input, be it single or multiple, and the capacity to remember such information. In particular, newborns can discriminate almost all the vowel and consonant contrasts used in the world's languages (Jusczyk, 1985), and are able to differentiate utterances from two languages if these belong to different rhythmic classes (Mehler et al., 1988). Two- to four-month-olds learn to distinguish languages belonging to the same rhythmic class (Bosch \& Sebastián-Gallés, 1997). Later on, in the second half of their first year, infants show changes in phonetic discrimination following exposure to the native language(s) (Werker \& Tees, 1984). In the case of monolingual exposure, children demonstrate realignment to the phonetic boundaries of one language; in bilingual situations, language-specific perceptual abilities develop in two languages, at least for highly frequent phones (Burns, Yoshida, Hill, \& Werker, 2007; Sundara, Polka, \& Molnar, 2008). When it comes to learning regularities in the input, preverbal 12-month-old bilingual infants, as opposed to monolinguals, show no problem learning multiple speech structures at the same time (Kovacs \& Mehler, 2009b). This suggests that infants exposed to two or more languages from birth are innately prepared to phonetically process and learn regularities from multiple native languages and multilingualism does not delay nor compromise the development of linguistic representation.

It is possible, then, these powerful perceptual abilities serve as the basis upon which multilingual-to-be children build separate representations for each language. By the end of their first year, for instance, preverbal children have already acquired a great deal about the sounds, sound patterns, word structures, and word order regularities of their input languages, and this knowledge could lay the foundations for the development of separate lexical, phonological, and morphosyntactic systems. At the same time, by interacting with monolingual speakers of different languages, young multilinguals would also learn to modify their language use on-line following relevant characteristics of the situation, in particular, the language preference(s) of their interlocutor, thereby developing multilingual communicative competence. That some elements of multilingual competence are already present before the onset of meaningful speech is not unlikely: Maneva and Genesee (2002), focusing on an analysis of utterance and syllable structure, temporal organization, and vowel and consonant inventories in a child's babbling in different language contexts, found evidence of language-specific patterning and, thus, some differentiation even before the appearance of the first words. More recent research indicates that differentiated babbling might even emerge with as little as five hours of language exposure. Ward, Sundara, Conboy, and Kuhl (2009) found indeed that 9- and 10-month-old infants from monolingual English-speaking homes produced systematically longer utterances and more multi-syllabic productions in a Spanish session after being exposed to five hours of Spanish during a six-week period. While differentiated babbling in these circumstances might not be evidence of multiple language representations, this research makes clear that infants are particularly sensitive to the linguistic details present in their surrounding. In the case of systematic exposure to three languages, then, the development of three language systems might follow naturally from infants' powerful perceptual and distributional learning abilities.

This hypothesis raises questions about whether exposure to three rather than two sets of input might compromise or facilitate the development of separate language systems. On the one hand, the possibility exists that a relatively large amount of input is necessary to learn each language, and thus that productive trilingualism takes longer to develop than bilingualism. Although this case study provides no evidence of such a delay, Quay (2001) and Chevalier's (2011) studies show that not all children who are systematically exposed to three languages become productive trilinguals. On the other hand, it has also been argued that increased input diversity might aid the child in the process of initially discriminating - and eventually building - separate language systems. As put by Bosch and Sebastián-Gallés (2001), simultaneous exposure to more than one language might even lead to an "enhanced language discrimination capacity," because, in multilingual environments, infants "have increasing opportunities to detect [...] in their somewhat complex input $[\ldots]$ certain incongruent cues or heterogeneous sound patterns" (p. 79). The discovery of such cues might refine infants' discrimination abilities, making language differentiation "precociously available." At the same time, consistent experience with three languages before the onset of speech - and the need to successfully monitor and keep separate the linguistic representations of three languages - might also lead to increased metalinguistic awareness, and, overall, to a domain-general enhancement of the cognitive control system, allowing children to efficiently acquire each language. Kovacs and Mehler (2009a) have recently shown this to be the case in bilinguals. In three eye-tracking studies, 7-month-old infants exposed to two languages from birth displayed improved cognitive control abilities compared to matched monolinguals, as measured by their ability to suppress a previously learned response and produce a new behavior following new task requirements. It is not ruled out that even more benefits are experienced by trilinguals. As put by Hoffman (2001): 
With regard to trilinguals the experience of three different languages also results in further enhanced awareness of the analysis and control components of processing to enable the speaker to make the right choices and respond in linguistically and communicatively adequate ways. In bilinguals, the choices available are three: language A or language B or both simultaneously. Trilinguals' choices are, potentially, considerably more numerous. (p. 14)

The evidence presented in this case study is not sufficient to support the claim that trilingual exposure results in enhanced executive functions and earlier metalinguistic awareness than bilingual exposure. However, the fact that signs of lexical, phonological, word order, and pragmatic differentiation were all present before age two - and before it was found in some bilingual studies - suggests that this issue deserves more attention in future studies. Of particular interest is also the question of what upper limit of language exposure might truly result in multilingual learning. In other words, how many languages can a young infant simultaneously hear from birth without this ultimately disrupting the typical time course of language acquisition and language representation? All these are exciting topics for future exploration.

\subsection{The Importance of Psychological and Social Factors in Infant Trilingualism}

A related issue is the role played by linguistic, psychological, and social factors in the process of trilingual learning. The few studies on early trilingualism make clear that children might adopt dramatically different strategies to deal with their multilingual resources: some children might show signs of trilingual competence from quite early in development, while others might fail to develop and use three languages. The issue at stake then is what allows children to become productive in three languages in their first years of life? Is it sufficient exposure to each language? Is it linguistic relatedness among languages? Is it psychological or personality-related factors? Is it a social context that strongly supports trilingualism?

Although this case study has focused on only one child (and hence its results cannot be generalized to all trilingually-exposed children), it has shown that all these factors might be important. First, Kathryn's exposure to each language was never below approximately $25 \%$, a percentage that has been considered sufficient to establish productive bilingualism (Pearson, Fernández, Lewedeg, \& Oller, 1997). This means that she heard enough of each language to learn sounds, words, and ordering patterns in Tagalog, Spanish, and English. Recent, preliminary analyses of TFLA in two sisters learning Italian, Spanish and English in Los Angeles also support the hypothesis that productive trilingualism might be dependent upon that $25 \%$ of minimal exposure to each language (Montanari, 2011b). Similarly to Kathryn, these sisters heard enough English (23.8\%), Spanish (33.3\%) and Italian (42.8\%) (from birth to age four) to be able to learn words and produce sentences in each of these languages. Given that input is considerably more divided in trilingual situations than in bilingual ones, it is very likely that many children raised with three languages do not indeed hear enough of a second or third language to learn and become productive in them. Clearly, more studies are needed to examine what is the lower limit of language exposure that yields productive trilingualism.

Second, Kathryn was learning languages with a relatively high degree of phonological and lexical overlap. Learning languages with many similar phones appeared to have helped the child build three advanced inventories over the same period of time monolinguals build one. At the same time, learning cognate languages seemed to have bootstrapped the buildup of three lexical systems. Recall that close to one third of Kathryn's words by age two (28\%) were indeed neutrals, i.e. items that were common to or phonetically similar across languages. These words helped the child communicate effectively in multiple languages and, thus, overcome the limitations brought about by memory limits and the cognitive load of having to learn three labels for each object or concept. Preliminary analyses of lexical development in the two Italian-Spanish-English trilingual sisters mentioned above (Montanari, 2011b) also confirm the idea that learning words in lexically-related languages might be facilitated. These analyses show that neutral or cognate items made up $36 \%$ of all words produced by one sister by age $1 ; 6$ and $41 \%$ of all words known by the other by age $2 ; 0$. Most importantly, the vast majority of these words ( $92 \%$ for one sister and $76 \%$ for the other) were Italian/Spanish, phonetically similar cognates (such as elefantelelefante, "elephant," casa/casa, "house," mosca/mosca, "fly") that could easily make the child equally productive in Italian and Spanish. Taken together, these findings suggest that productive trilingualism might be more easily attained when cognate languages are at play because lexical development in one language might bootstrap lexical development in the other.

A variety of bilingual studies have shown that interaction between the two languages of bilingual children might aid in the acquisition process, allowing for a similar rate of development in bilinguals and monolinguals (Fabiano-Smith \& Barlow, 2010; Fabiano-Smith \& Goldstein, 2010b) and even for a faster rate of acquisition for some language constructs in bilinguals (see Gawlitzek-Maiwald \& Tracy, 1996, for syntax and Goldstein \& Bunta, 2012, for phonology). In these studies, however, children were learning languages with a certain degree of structural or phonological overlap. An interesting question then is to examine the emergence of separate phonological, lexical, 
and syntactic systems in children learning phonologically-unrelated, non-cognate, and typologically distant languages. On the one hand, it is possible that these children might take longer to build three languages than the child in this study. On the other hand, it is not excluded that, even in the case of unrelated languages, the development of certain elements in one language might aid in the development of the same elements in other languages. In Kathryn's study, for instance, the formation of non-cognate equivalent triplets was facilitated by the existence of doublets. In other words, even when the child was learning phonetically different words, learning a third label for a concept took less time than learning a second, suggesting that this process might have been aided by the child's familiarity with the concept and with the experience of learning equivalents. A similar process has been observed in bilingual third language learners, who, by exploiting knowledge of and experience with two languages, have been found to learn a third with relative ease compared to monolinguals (see Cenoz, 2003, for a review). Clearly, the hypothesis that knowledge in one language "bootstraps" knowledge in other languages deserves to be tested with children learning languages with varying degrees of cognation and typological overlap.

Psychological and personality-related factors and the overall social context in which Kathryn was acquiring her languages might have also in part determined the child's success in developing three linguistic systems. Kathryn was indeed a very extroverted child, eager to communicate, and not afraid to make mistakes, traits that have all been associated with successful and rapid second language learning (Paradis, Genesee, \& Crago, 2011). Also, Kathryn, just as the Italian-Spanish-English trilingual sisters in Montanari's (2011b) study, was motivated to acquire all three languages, since these were used on a daily basis by speakers who played with her, read to her and, overall, engaged her in extensive interactions. As Hoffman (2001) puts it, "certain social, cultural and, above all, psychological and personality-related factors may assume disproportionately high significance in influencing trilingual competence, as compared with their influence in the case of bilingual competence" (p.2) and they might fully explain why some children become fluent trilinguals while others fail. Future studies should, therefore, examine the extent to which learning style, motivation, and the support of the social context play a role in early trilingual development.

Finally, granted that developing trilinguals do indeed develop separate language systems from early on in development, more research should assess the degree of interdependence between such systems. As pointed out above, many studies have indeed found, especially during later phonological and syntactic development, evidence for cross-language interaction despite the existence of clearly distinct phonological and syntactic systems (see Yip \& Matthews, 2007, for a review). Paradis and Genessee (1996), in particular, have proposed that different types of interaction might occur: (1) transfer, when elements specific to one language are used in productions of the other language; (2) deceleration, when interaction between the two languages interferes with, and thus slows down, the rate of acquisition; and (3) acceleration, when interaction between two languages aids in, and thus speeds up, the acquisition process. Although this study has only found evidence of acceleration as pointed out above, it is not ruled out that transfer, acceleration, and deceleration might indeed occur at the same time for different language aspects (see, for instance, Fabiano-Smith \& Goldstein, 2010b, and Fabiano-Smith \& Barlow, 2010). Evidently, there is need for more research that examines the issue of interdependence in groups of bilinguals and trilinguals instead that in individual children.

In conclusion, I believe that this case study is a step forward towards gaining deeper insights into the process of language development in trilingual children. This study has shown indeed that, given sufficient input in each language, a child can show signs of multiple language systems, and thus of trilingual competence, even before age two. It remains to be seen whether Kathryn will become a proficient trilingual in the years to come. This study has shown that the initial build-up of separate linguistic systems might be a natural step in the course of becoming trilingual; yet, it is not a sufficient condition to develop and maintain productive trilingualism. As Gathercole and Thomas (2009) have shown, only consistent exposure to these languages throughout development and a social context that strongly supports trilingualism will allow the child to maintain her multilingual abilities and become a successful member of three language communities.

\section{References}

Barnes, J. (2011). The influence of child-directed speech in early trilingualism. International Journal of Multilingualism, 8(1), 42-62. http://dx.doi.org/10.1080/14790711003671861

Barnes, J. D. (2006). Early trilingualism: a focus on questions. Clevedon, UK: Multilingual Matters.

Bosch, L., \& Sebastián-Gallés, N. (1997). Native-language recognition abilities in 4-month-old infants from monolingual and bilingual environments. Cognition, 65(1), 33-69. 
http://dx.doi.org/10.1016/S0010-0277(97)00040-1

Bosch, L., \& Sebastián-Gallés, N. (2001). Early language differentiation in bilingual infants. In J. Cenoz \& F. Genesee (eds.), Trends in bilingual acquisition (pp. 71-93). Philadelphia: John Benjamins Publishing Company.

Browman, C., \& Goldstein, L. (1992). Articulatory Phonology: an overview. Phonetica, 49, 155-180. http://dx.doi.org/10.1159/000261913

Burns, T. C., Yoshida, K. A., Hill, K., \& Werker, J. F. (2007). The development of phonetic representation in bilingual and monolingual infants. Applied Psycholinguistics, 28(3), 455-474. http://dx.doi.org/10.1017/S0142716407070257

Cenoz, J. (2003). The additive effect of bilingualism on third language acquisition. International Journal of Bilingualism, 7, 71-88. http://dx.doi.org/10.1177/13670069030070010501

Cenoz, J., \& Hoffman, C. (2003) (eds.). The effect of bilingualism on third language acquisition. Special issue of The International Journal of Bilingualism, 7(1). http://dx.doi.org/10.1177/13670069030070010501

Chevalier, S. (2011). Trilingual language acquisition. Contextual factors influencing active trilingualism in early childhood. Unpublished habilitation thesis, Univeristy of Zurich.

Deuchar, M., \& Quay, S. (2000). Bilingual acquisition. Theoretical implications of a case study. Oxford: Oxford University Press.

Edwards, M., \& Dewaele, J.-M. (2007). Trilingual conversations: a window into multicompetence. International Journal of Bilingualism, 11(2), 221-242. http://dx.doi.org/10.1177/13670069070110020401

Fabiano-Smith, L., \& Barlow, J. (2010). Interaction in bilingual phonological acquisition: evidence from phonetic inventories. The International Journal of Bilingual Education and Bilingualism, 31 (1), 1-17. http://dx.doi.org/10.1080/13670050902783528

Fabiano-Smith, L., \& Goldstein, B. (2010a). Early-, middle-, and late-developing sounds in monolingual and bilingual children: an exploratory investigation. American Journal of Speech-Language Pathology, 19(1), 66-77. http://dx.doi.org/10.1044/1058-0360(2009/08-0036)

Fabiano-Smith, L., \& Goldstein, B. (2010b). Phonological acquisition in bilingual Spanish-English speaking children. Journal of Speech, Language, and Hearing Research, 53, 160-178. http://dx.doi.org/10.1044/1092-4388(2009/07-0064)

Gathercole, V. M., \& Thomas, E. M. (2009). Bilingual first-language development: dominant language takeover, threatened minority language take-up. Bilingualism: Language and Cognition, 12(2), 213-237. http://dx.doi.org/10.1017/S1366728909004015

Gawlitzek-Maiwald, I., \& Tracy, R. (1996). Bilingual bootstrapping. Linguistics, 34, 901-926. http://dx.doi.org/10.1515/ling.1996.34.5.901

Genesee, F., \& Nicoladis, E. (2009). Bilingual first language acquisition. In E. Hoff \& M. Shatz (eds.), Blackwell handbook of language development (pp. 324-342). Malden, MA: Wiley-Blackwell.

Goldstein, B., \& Bunta, F. (2012). Positive and negative transfer in the phonological systems of blingual speakers. International Journal of Bilingualism, 16(4), 388-401. http://dx.doi.org/10.1177/1367006911425817

Hoffman, C. (2001). Towards a description of trilingual competence. The International Journal of Bilingualism, 5(1), 1-17. http://dx.doi.org/10.1177/13670069010050010101

Hoffman, C., \& Stavans, A. (2007). The evolution of trilingual codeswitching from infancy to school age: the shaping of trilingual competence through dynamic language dominance. International Journal of Bilingualism, 11(1), 55-72. http://dx.doi.org/10.1177/13670069070110010401

Holowka, S., Brosseau-Lapré, F., \& Petitto, L. A. (2002). Semantic and conceptual knowledge underlying bilingual babies" first signs and words. Language Learning, 52(2), 205-262. http://dx.doi.org/10.1111/0023-8333.00184

Johnson, C., \& Wilson, I. (2002). Phonetic evidence for early language differentiation: Research issues and some preliminary data. International Journal of Bilingualism, 6(3), 271-289. http://dx.doi.org/10.1177/13670069020060030401

Jusczyk, P. W. (1985). On characterizing the development of speech perception. In J. Mehler \& R. Rox (eds.), Neonate cognition: beyond the blooming, buzzing confusion (pp. 199-229). Hillsdale, NJ: Erlbaum. 
Kazzazi, K. (2011). Ich brauche mix-cough: cross-linguistic influence involving German, English and Farsi. International Journal of Multilingualism, 8(1), 63-79. http://dx.doi.org/10.1080/14790711003671879

Kehoe, M., Lleó, C., \& Rakow, M. (2004). Voice onset time in bilingual German-Spanish children. Bilingualism: Language and Cognition, 7(1), 71-88. http://dx.doi.org/10.1017/S1366728904001282

Keshavarz, M. H., \& Ingram, D. (2002). The early phonological development of a Farsi-English bilingual child. International Journal of Bilingualism, 6(3), 255-269. http://dx.doi.org/10.1177/13670069020060030301

Kovacs, A. M., \& Mehler, J. (2009a). Cognitive gains in 7-month-old bilingual infants. Proceedings of the National Academy of Sciences of the United States of America, 106(16), 6556-6560. http://dx.doi.org/10.1073/pnas.0811323106

Kovacs, A. M., \& Mehler, J. (2009b). Flexible learning of multiple speech structures in bilingual infants. Science, 325(5940), 611-612. http://dx.doi.org/10.1126/science.1173947

Lanvers, U. (1999). Lexical growth patterns in a bilingual infant: the occurrence and significance of equivalents in the bilingual lexicon. International Journal of Bilingual Education and Bilingualism, 2(1), 30-52. http://dx.doi.org/10.1080/13670059908666245

Lanza, E. (1997). Language mixing in infant bilingualism: a sociolinguistic perspective. Oxford, UK: Clarendon Press.

Maneva, B. (2004). "Maman, je suis polyglotte!": a case study of multilingual language acquisition from 0-5 years. International Journal of Multilingualism, 1(2), 109-122. http://dx.doi.org/10.1080/14790710408668182

Maneva, B., \& Genesee, F. (2002). Bilingual babbling: evidence for language differentiation in dual language acquisition. In B. Skarabela, S. Fish \& A. H.-J. Do (eds.), Proceedings of the $26^{\text {th }}$ annual Boston University Conference on Language Development (pp. 383-392). Somerville, MA: Cascadilla Press.

Mehler, J., Jusczyk, P. W., Lambertz, G., Halsted, N., Bertoncini, J., \& Amiel-Tison, C. (1988). A precursor of language acquisition in young infants. Cognition, 29, 143-178.

Meisel, J. M. (2001). The simultaneous acquisition of two first languages: early differentiation and subsequent development of grammars. In J. Cenoz \& F. Genesee (eds.), Trends in bilingual acquisition (pp. 11-41). Philadelphia: John Benjamins Publishing Company.

Montanari, S. (2009a). Pragmatic differentiation in early trilingual development. Journal of Child Language, 36, 597-627. http://dx.doi.org/10.1017/S0305000908009112

Montanari, S. (2009b). Multi-word combinations and the emergence of differentiated ordering patterns in early trilingual development. Bilingualism: Language and Cognition, 12(4), 503-519. http://dx.doi.org/10.1017/S1366728909990265

Montanari, S. (2010). Translation equivalents and the emergence of multiple lexicons in early trilingual development. First Language, 30(1), 102-125. http://dx.doi.org/10.1177/0142723709350528

Montanari, S. (2011a). Phonological differentiation before age two in a Tagalog-Spanish-English trilingual child. International Journal of Multilingualism, 8(1), 5-21. http://dx.doi.org/10.1080/14790711003671846

Montanari, S. (2011b). Language transfer in the case of cognate languages: evidence from developing trilingual children. Invited presentation at California State University, Long Beach, Long Beach, November 4.

Paradis, J., \& Genesee, F. (1996). Syntactic acquisition in bilingual children: autonomous or independent? Studies in Second Language Acquisition, 18, 1-25. http://dx.doi.org/10.1017/S0272263100014662

Paradis, J., Genesee, F., \& Crago, M. (2011). Dual language development and disorder (2 ${ }^{\text {nd }}$ ed.). Baltimore, MD: Brookes.

Pearson, B. Z., Fernández, S. C., \& Oller, D. K. (1995). Cross-language synonyms in the lexicons of bilingual infants: One system or two? Journal of Child Language, 22, 345-68. http://dx.doi.org/10.1017/S030500090000982X

Pearson, B. Z., Fernández, S. C., Lewedeg, V., \& Oller, D. K. (1997). The relation of input factors to lexical learning by bilingual infants. Applied Psycholinguistics, 18, 41-58. http://dx.doi.org/10.1017/S0142716400009863

Quay, S. (2001). Managing linguistic boundaries in early trilingual development. In J. Cenoz \& F. Genesee (eds.), Trends in bilingual acquisition (pp. 149-199). Philadelphia: John Benjamins Publishing Company.

Quay, S. (2008). Dinner conversations with a trilingual two-year-old: Language socialization in a multilingual context. 
First Language, 28(1), 5-33. http://dx.doi.org/10.1177/0142723707083557

Quay, S. (2011a). Introduction: Data-driven insights from trilingual children in the making. International Journal of Multilingualism, 8(1), 1-4. http://dx.doi.org/10.1080/14790711003671838

Quay, S. (2011b). Trilingual toddlers at daycare centers: the role of caregivers and peers in language development. International Journal of Multilingualism, 8(1), 22-41. http://dx.doi.org/10.1080/14790711003671853

Rau, D. H. V. (1992). Language contact in the Philippines. Philippine Journal of Linguistics, 23, 91-109.

Stavans A., \& Muchnik, M. (2008). Language production in trilingual children: insights on code switching and code mixing. Sociolinguistic Studies, 1(3), 483-511. http://dx.doi.org/10.1558/sols.v1i3.483

Stavans, A., \& Swisher, V. (2006). Language switching as a window on trilingual acquisition. International Journal of Multilingualism, 3, 193-220. http://dx.doi.org/10.2167/ijm020.0

Sundara, M., Polka, L., \& Molnar, M. (2008). Development of coronal stop perception: bilingual infants keep pace with their monolingual peers. Cognition, 108, 232-242. http://dx.doi.org/10.1016/j.cognition.2007.12.013

Wang, X. (2008). Growing up with three languages. Buffalo, NY: Multilingual Matters.

Ward, N., Sundara, M., Conboy, B., \& Kuhl, P. (2009). Consequences of short - term language exposure in infancy on babbling. Poster presented at the 158th Meeting of the Acoustical Society of America. San Antonio, Texas, October 26-30.

Werker, J. F., \& Tees, R. C. (1984). Cross-language speech perception: evidence for perceptual reorganization during the first year of life. Infant Behavior and Development, 7, 49-63. http://dx.doi.org/10.1016/S0163-6383(84)80022-3

Yip, V., \& Matthews, S. (2007). The bilingual child: Early development and language contact. Cambridge, UK: Cambridge University Press. http://dx.doi.org/10.1017/CBO9780511620744

\section{Note}

Note 1. Since the probability of matching a specific gestural property varied from language to language depending on the number of contrasts made by each language for each gestural property (for example, the probability of reproducing location is higher in Spanish, which contrasts eight places of articulation, than it is in English, which contrasts thirteen), chance levels were calculated by randomly pairing, 100,000 times, the child's word-initial segments and the target forms within each language. The average percentage of segments that shared the indicated gestural property in the randomized data was then taken as chance level (see Montanari, 2011a, for more detailed information on the method). 